\title{
Cariprazine in Therapy of Delusions with a Therapeutic Resistance due to Traumatic Brain Injury Randomized, Double- Blind Placebo-Controlled Study
}

\author{
NA Aliyev ${ }^{*}$ and ZN Aliyev ${ }^{2}$ \\ ${ }^{1}$ Azerbaijan State Advanced Training Institute, department of psychiatry and drug addiction, Baku, Azerbaijan. \\ ${ }^{2}$ Azerbaijan Medical University, department of psychiatry Baku, Azerbaijan.
}

*Corresponding author: Nadir A. Aliyev, Department of psychiatry and addiction, Azerbaijan State Advanced Training Institute, Baku, Azerbaijan.

Received Date: September 23 2021; Accepted Date: October 26, 2021; Published Date: November 16, 2021

Citation: NA Aliyev and ZN Aliyev (2021) Cariprazine in Therapy of Delusions with a Therapeutic Resistance due to Traumatic Brain Injury Randomized, Double-Blind Placebo-Controlled Study J, Psychology and Mental Health Care. 5(2); DOI: 10.31579/2637-8892/143

Copyright: (C) 2021, NA Aliyev, This is an open access article distributed under the Creative Commons Attribution License, which permits unrestricted use, distribution, and reproduction in any medium, provided the original work is properly cited.

\begin{abstract}
Objective: We studied cariprazine in therapy of delusions with a therapeutic resistance due to traumatic brain injury randomized, double-blind placebo-controlled study manner.

Methods: to traumatic brain injury hundred patients (100 all men) whom we studied were under observation in Mental Health Center of the Ministry of Health of the Republic of Azerbaijan from January 2020 to June 2021. The method of randomization was given by lottery. Each patient was randomized to receive either in agreement of the instruction cariprazine (50 patients) over 5 day in dose $6 \mathrm{mg}$ one times per os in morning after meet for 6 weeks or matched placebo (50 patients) in a double-blind manner. A structured clinical interview, for DSM-5Axis I Disorder, Patient Edition, was used to diagnose according to DSM-5 major or mild neurocognitive disorder due to traumatic brain injury.
\end{abstract}

Results: All patients (50) treated with cariprazine treated participants responded by 6 weeks, versus two of the 50 placebotreated participants $(\mathrm{p}<0.001)$. The most common and problematic side effect in the cariprazine group was not.

Conclusions: The authors believe this to be the first double-blind placebo-controlled randomization study to test the efficacy of a cariprazine in the management of in therapy of delusions with a therapeutic resistance due to traumatic brain injury randomized, double-blind placebo-controlled study manner. They need to be replicated in a larger study group.

Keywords: cariprazine; delusions; therapeutic resistance; due to traumatic brain injury

\section{Introduction}

Cariprazine (vraylar, reaqilq) is an antipsychotic of the new generation, which is a particle agonist of dopamine receptors. The drug differs from other antipsychotics with high affinity to D3-dopamine receptors, which is about 10 times higher than other drugs. It is believed that D3-receptors play an important role in the modulation of cognitive processes and emotional regulation. These pharmacological properties of the drug determine the intended clinical targets in patients with schizophrenia. The obtained data demonstrate the predominance of cariprazine in the dominant clinical picture with negative symptoms and simultaneous favorable tolerance profile [1-3].

The prevalence of traumatic brain injury in the United States, 1.7 million cases occur each year, resulting in 1.4 million emergency department visits, 275,000 hospitalizations, and 52,000 deaths. About $2 \%$ of the population lives with TBI-related disabilities. In the United States, 59\% of TBI cases are in men. The most common causes of TBI in the United States are falls, car accidents and headaches. Collisions and head blows during contact sports are increasingly recognized as a source of mild TBIs, as recurrent mild TBIs can lead to cumulative long-term consequences [4].

\section{Materials and methods}

This was a double-blind, placebo-controlled trial for patients diagnosed with DSM-5 for Delusions with a therapeutic resistance due to traumatic brain injury. The patients gave their informed, written consent to participate. In accordance with the Helsinki Declaration of the World Medical Association "Recommendations for doctors engaged in 
biomedical research involving people", adopted by the 18th World Medical Assembly (Finland, 1964, revised in Japan in 1975, Italy - 1983, Hong Kong - 1989, the South African Republic - 1996, Edinburgh 2000); The Constitution of the Republic of Azerbaijan, the Law "On Psychiatric Assistance" (adopted on 12.06.2001, with amendments and additions - 11.11.2011, Decisions of the Cabinet of Ministers of the Republic of Azerbaijan No. 83, dated April 30, 2010 "On Approval of the Rules for Conducting Scientific, Preclinical and Clinical studies of medicines" are established. The conditions of the conducted researches corresponded to the generally accepted norms of morality, the requirements of ethical and legal norms, as well as the rights, interests and personal dignity of the participants of the studies were observed.

The study periods: from January 2020 to June 2021. Patients were observed at the Mental Health Center of the Ministry of Health of the Republic of Azerbaijan. This was a double-blind, placebo-controlled trial for patients diagnosed with DSM-5 for Delusions with a therapeutic resistance due to traumatic brain injury.
Hundred patients (100 all men) whom we studied were under observation in Mental Heals Center of the Azerbaijan Republic from January 2020 to June 2021. The method of randomization was given by lottery. Each patient was randomized to receive either in agreement of the instruction cariprazine (50 patients) over 5 day in dose $6 \mathrm{mg}$ one times per os in morning after meet for 6 weeks or matched placebo (50 patients) in a double-blind manner. A structured clinical interview, for DSM-5Axis I Disorder, Patient Edition, was used to diagnose according to DSM-5 major or mild neurocognitive disorder due to traumatic brain injury. Eligible participants were required to be between 18 and 65 years of age.

Analysis of response refers to the last observation carried forward for all subjects who had valuables efficacy at baseline and with treatment. The responder analysis was conducted by using the chi-square (x2) and analysis of variance (ANOVA) according to Glantz [5].

\section{Results}

Characteristics of the patients randomly assigned to the two treatments are shown in table 1

\begin{tabular}{|l|c|c|}
\hline Characteristic & Cariprazine $\mathrm{n}=50$ & Placebo $\mathrm{n}=50$ \\
\hline & Mean SD & Mean SD \\
\hline Age (years) & $37.3 \pm 9.2$ & $38.3 \pm 9.8$ \\
\hline Duration of illness in month & $6,1 \pm 0,5$ & $5,8 \pm 0,7$ \\
\hline Education: & $28(56 \%)$ & $30(60 \%)$ \\
- primary school & $22(44 \%)$ & $20(40 \%)$ \\
- secondary school & $10(20 \%)$ & $10(20 \%)$ \\
\hline Marital status: & $30(60 \%)$ & $28(56)$ \\
- never married & $10(20)$ & $12(24)$ \\
- married & $18(36 \%)$ & $22(44 \%)$ \\
\hline Employmed or separated & $32(64 \%)$ & $28(56)$ \\
\hline - unemployed & employed & \\
\hline
\end{tabular}

Note: differences between groups are not significant

\section{Table1. Sociodemographic characteristics of patients}

Statistical differences between the two groups are no significantly. The results of treatment are shown in Table 2. Response was defined as a 100\% reduction in the symptoms of Delusions with a therapeutic resistance due to traumatic brain injury. The responder was conducted by $\mathrm{X}^{2}$ demonstrated superior for than for placebo (Table2). Cariprazine was generally well tolerated by the patients in the study. The two common side effects

\begin{tabular}{|l|l|l|l|}
\hline \multirow{2}{*}{ Treatment Groups } & Observed number & Expected number & chi-square $\left(\mathrm{x}^{2}\right)$ \\
\cline { 2 - 4 } & Yes improvement* & Not improvement* & Total \\
\hline Placebo & $2(12.43)$ & $48(11.57)$ & 50 \\
\hline Cariprazine & $48(13.56)$ & $2(8,0.43)$ & 50 \\
\hline Total & 50 & 50 & 100 \\
\hline
\end{tabular}

Note: expected numbers indication in the brackets $\%^{2}=22.68, \mathrm{df}=1, p<0.001$.

\section{Table 2. The results of the square analysis.}

\section{Discussion}

\section{Delusions}

Delusions are fixed beliefs that are not amenable to change in light of conflicting evidence. Their content may include a variety of themes (e.g., persecutory, referential, somatic, religious, grandiose). Persecutory delusions (i.e., belief that one is going to be harmed, harassed, and so forth by an individual, organization, or other group) are most common. Referential delusions (i.e., belief that certain gestures, comments, environmental cues, and so forth are directed at oneself) are also common. Grandiose delusions (i.e., when an individual believes that he or she has exceptional abilities, wealth, or fame) and erotomanic delusions (i.e., leading to discontinuation in the cariprazine group were allergic reaction and drowsiness, sweating a frequent complaint during placebo treatment occurred in two of $50 \mathrm{men}$. There were not unexpected or serious adverse events. From Cariprazine group patients improvement observed in 48 while in the placebo group, improvement was noted in only 2 patients. when an individual believes falsely that another person is in love with him or her) are also seen. Nihilistic delusions involve the conviction that a major catastrophe will occur, and somatic delusions focus on preoccupations regarding health and organ function.

Delusions are deemed bizarre if they are clearly implausible and not understandable to same-culture peers and do not derive from ordinary life experiences. An example of a bizarre delusion is the belief that an outside force has removed his or her internal organs and replaced them with someone else's organs without leaving any wounds or scars. An example of a nonbizarre delusion is the belief that one is under surveillance by the police, despite a lack of convincing evidence. Delusions that express a 
loss of control over mind or body are generally considered to be bizarre; these include the belief that one's thoughts have been "removed" by some outside force (thought withdrawal), that alien thoughts have been put into one's mind (thought insertion), or that one's body or actions are being acted on or manipulated by some outside force (delusions of control). The distinction between a delusion and a strongly held idea is sometimes difficult to make and depends in part on the degree of conviction with which the belief is held despite clear or reasonable contradictory evidence regarding its veracity.

Cariprazine is an antipsychotic of the new generation, which is a particle agonist of dopamine receptors. The drug differs from other antipsychotics with high affinity to D3-dopamine receptors, which is about 10 times higher than other drugs. It is believed that D3-receptors play an important role in the modulation of cognitive processes and emotional regulation. These pharmacological properties of the drug determine the intended clinical targets in patients with schizophrenia. The obtained data demonstrate the predominance of cariprazine in the dominant clinical picture with negative symptoms and simultaneous favorable tolerance profile [1-3].

As you know, antipsychotics are the main pharmacological agent used in schizophrenia. Their obligatory property is the ability to reduce psychotic symptoms, as well as psychomotor agitation. At the same time, various clinical manifestations of schipsophrenia determine the need to influence also other groups of symptoms, primarily negative, affective disorders and cognitive impairments. Apparently, such a multimodal action of the antipsychotic drug at the stage of long-term therapy is necessary, but with active and continued therapy, it is also desirable.

With the traditional and current classification of drugs by clinical action, sedatives, incisive and de-inhibiting antipsychotics are distinguished. In the practical work of a psychiatrist, this taxonomy is still often fundamental in the adoption of a rational choice of an antipsychotic in various clinical situations. At the same time, however, there are costs of such "excess" commitment. In particular, the use of drugs with disinhibitory activity in patients with psychotic symptoms is limited, where they may also be effective. In addition, the classification does not consider drugs with a broad multi-receptor mechanism of action and universal clinical activity.

Kariprazine is a registered drug under the name reagila in various dosages in Azerbaijan. As provided by the instructions for this antipsychotic drug, it is intended for the treatment of schizophrenia and is recommended for use at the stages of active, continued and long-term therapy. The advantage of cariprazine over other antipsychotics is its proven efficacy in dominant negative symptoms. The presented work proved that cariprazine in therapy of auditory hallucinations in a patient with a therapeutic resistance due to traumatic brain injury is very effective.

Kariprazine has a 6-8-fold greater affinity for D3 receptors than for D2 receptors, with a specificity for the D3 receptor, which is 3-10 times higher than the specificity of aripiprazole for this receptor [6]. Aripiprazole binds more efficiently than cariprazine to human and rat 5HT2A, 5-HT2C and adrenergic receptors. In contrast, cariprazine has lower affinity for human and rat hippocampal 5-HT1A receptors (and exhibits low intrinsic efficacy), low affinity for human 5-HT2A receptors, moderate or low affinity for histamine $\mathrm{H} 1$ and 5-HT2C receptors, and negligible affinity for cholinergic or adrenergic receptors, all of which indicate a decrease in the propensity for side effects, are associated with these receptors.

\section{Conclusion}

Problems of pharmacological treatment of Delusions with a therapeutic resistance due to traumatic brain injury very problematic. Because classical and atypical antipsychotics cause serious extrapyramidal side effects. This is the first study on the use of cariperzine in therapy of delusions with a therapeutic resistance due to traumatic brain injury, randomized, double-blind placebo-controlled study. All patients (50) treated with cariprazine treated participants responded by 6 weeks, versus two of the 50 placebo-treated participants $(\mathrm{p}<0.001)$. The most common and problematic side effect in the cariprazine group was not.

Limitation of the study: First, our small study group and we recommend that these results be replicated in a larger group so that effect sizes can be more precisely estimated. Second, it is necessary study of possibility generalizability these data to women. Notwithstanding these limitations, this study suggests that, cariperzine are efficacious and well tolerated in the treatment of Delusions with a therapeutic resistance due to traumatic brain injury very.

\section{Author Disclosure Information}

The authors declare that the article is submitted on behalf of all authors. None of the material in the article has been published previously in any form and none of the material is currently under consideration for publication elsewhere other than noted in the cover letter to the editor. Authors declare no financial and personal relationship with other people or organizations that could inappropriately influence this work. All authors contributed to and have approved the final article. The authors declare no conflicts of interest. No sponsor provided funding for this study. Mental Health Center of the Ministry of Health of the Republic of Azerbaijan provided the outpatient unit, the material for clinical and neuro-psychological assessments, and electronic resources.

\section{Acknowledgment}

The authors would like to thank staff of the Mental Health Center of the Ministry of Health of the Republic of Azerbaijan.

\section{References}

1. Wolfgang Fleischhackera, Silvana Galderisib, István Laszlovszkyc, Balázs Szatmáric, Ágota Barabássyc, et al. (2019) The efficacy of cariprazine in negative symptoms of schizophrenia: Post hoc analyses of PANSS individual items and PANSS-derived factors. European Psychiatry 58 1-9.

2. Marder S., Fleischacker W., Lu K., Zhong Y., Nemeth G., Laszlovszky I., Durgam S. (2019) Efficacy of cariprazine across symptom domains in patients with acute exacerbation of schizophrenia: Pooled analyses from 3 phase II/III studies. Eur Neuropsychopharmacology 1, 127-139.

3. Alan F. Schatzberg, M.D. Charles B. Nemeroff, M.D., Ph.D. Text Book of Psychopharmacology. Fifth Edition Edited By. 2017 American Psychiatric Association Publishing pp.2879.

4. American Psychiatric Association Diagnostic and statistical manual of mental disorders. 5th ed. American Psychiatric Association, Arlington 2013.

5. Glantz A. (2012) Stanton. Primer of Biostatistics, Seventh Edition. 320 pages. ISBN 10: 0071781501 ISBN 13: 9780071781503

6. Mattingly G, Anderson R: (2016) Cariprazine for schizophrenia and bipolar I disorder. Current Psychiatry 15(2):34-39. 
This work is licensed under Creative Commons Attribution 4.0 License

To Submit Your Article Click Here:

Submit Manuscript

DOI: $10.31579 / 2637-8892 / 143$
Ready to submit your research? Choose Auctores and benefit from:

$>$ fast, convenient online submission

$>$ rigorous peer review by experienced research in your field

$>$ rapid publication on acceptance

$>$ authors retain copyrights

$>\quad$ unique DOI for all articles

$>$ immediate, unrestricted online access

At Auctores, research is always in progress.

Learn more https://www.auctoresonline.org/journals/psychology-andmental-health-care 